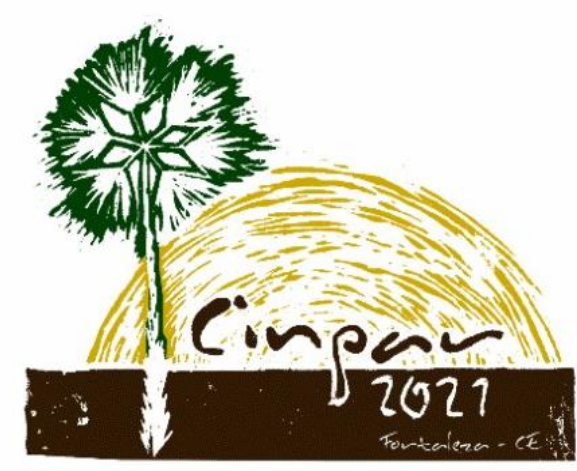

XVII Congresso Internacional sobre Patologia e

Reabilitação das Construções

XVII Congreso Internacional sobre Patología y Rehabilitación de las Construcciones

XVII International Conference on Pathology and Constructions Rehabilitation

FORTALEZA (Brasil), 3 a 5 de junho de 2021

https://doi.org/10.4322/CINPAR.2021.104

\title{
Manifestações Patológicas em Obra de Arte Especial Após Enchentes na Mata Sul de Pernambuco - Estudo de Caso da Ponte de Laje Grande
}

\section{Pathological Manifestations in Special Engineering Structure After Floods in the Mata Sul of Pernambuco - Case Study Over Laje Grande Bridge}

\author{
Valéria OLIVEIRA ${ }^{1}$, Angelo COSTA E SILVA², Camilla SANTOS ${ }^{3}$ \\ ${ }^{1}$ Universidade de Pernambuco, Recife-PE, Brasil, valeria.renielle@gmail.com \\ 2 Universidade de Pernambuco, Recife-PE, Brasil, angelo@tecomat.com.br \\ ${ }^{3}$ Universidade de Pernambuco, Recife-PE, Brasil, camilla2015lais@gmail.com
}

\begin{abstract}
Resumo: Importante para o funcionamento da sociedade, as pontes são obras de artes especiais que podem apresentar manifestações patológicas desde a fase da sua concepção à fase de uso, podendo comprometer sua durabilidade e funcionamento. Nesse contexto, a identificação e a avaliação dessas manifestações, para uma posterior intervenção e manutenção, quando necessário, é fundamental. Comumente, as pontes estão situadas em ambiente de forte agressividade ambiental, expostas a solicitações excepcionais, como chuvas intensas e inundações, como a Ponte de Laje Grande, localizada na área rural do município de CatendePernambuco. Sendo esse objeto do estudo de caso, através da análise de dados coletados após as chuvas que causaram inundações na Mata Sul pernambucana a terem atingido, no ano de 2017. Foram investigadas as manifestações patológicas, sendo identificadas fissuras, corrosão das armaduras, abrasão, lixiviação, eflorescências, presença de vegetação e danos ao guarda corpo. Além disso, foram apresentadas medidas necessárias para solução das mesmas. Espera-se com isso contribuir com a ampliação do conhecimento acerca do tema, e consequentemente, com a preservação dessas obras de artes especiais.
\end{abstract}

Palavras-chave Manifestações patólogicas. Pontes. Concreto. Inundações.

\begin{abstract}
Important for the functioning of society, bridges are special engineering structures that can present pathological manifestations from the stage of their conception to the stage of use, which can compromise their durability and functioning. In this context, the identification and evaluation of these manifestations, for later intervention and maintenance, when necessary, is essential. Commonly, the bridges are located in an environment of strong environmental aggressiveness, exposed to exceptional requests, such as intense rains and floods, such as the Laje Grande Bridge, located in the rural area of the municipality of CatendePernambuco. This being the object of the case study, through the analysis of data collected after the rains that caused floods in the Mata Sul of Pernambuco to have reached, in the year 2017. Pathological manifestations were investigated, with cracks, armor corrosion, abrasion, leaching, efflorescence, presence of vegetation and damage to the guardrail being identified. In addition, necessary measures were presented to resolve them. This is expected to contribute to the expansion of knowledge about the theme, and consequently, to the preservation of these special engineering structures.
\end{abstract}

Keywords: Pathological manifestations. Bridges. Concrete. Floods. 


\section{Introdução}

Pontes são obras de artes especiais que possuem grande importância na sociedade, uma vez que suprem a necessidade de transpor barreiras, encurtar distâncias e interligar pessoas. Essas estruturas podem ser constituídas de vários materiais, combinados ou não, como o concreto armado, aço, madeira, entre outros. Uma obra de arte de concreto armado pode apresentar manifestações patológicas desde a sua fase de concepção à sua fase de uso, esse último podendo ocorrer devido ao uso inadequado da estrutura, falta de manutenção e até devido solicitações excepcionais, como chuvas intensas e inundações.

Diante do exposto, o artigo apresentará um estudo de caso sobre a Ponte de Laje Grande, localizada na área rural do munícipio de Catende - PE, para identificar e avaliar as manifestações patológicas encontradas em inspeção realizada após as fortes chuvas que ocasionaram inundações em cidades da Mata Sul pernambucana.

\section{Definições dos elementos estruturais de pontes}

Ponte pode ser caracterizada como a obra de arte especial destinada a transpor um obstáculo, sendo esse constituído por água, permitindo a continuidade de uma via (MARCHETTI, 2018; VITÓRIO, 2002). Os elementos estruturais que compõe as pontes são a superestrutura, a mesoestrutura e a infraestrutura, Figura 1 , que em conjunto garantem a estabilidade da estrutura.

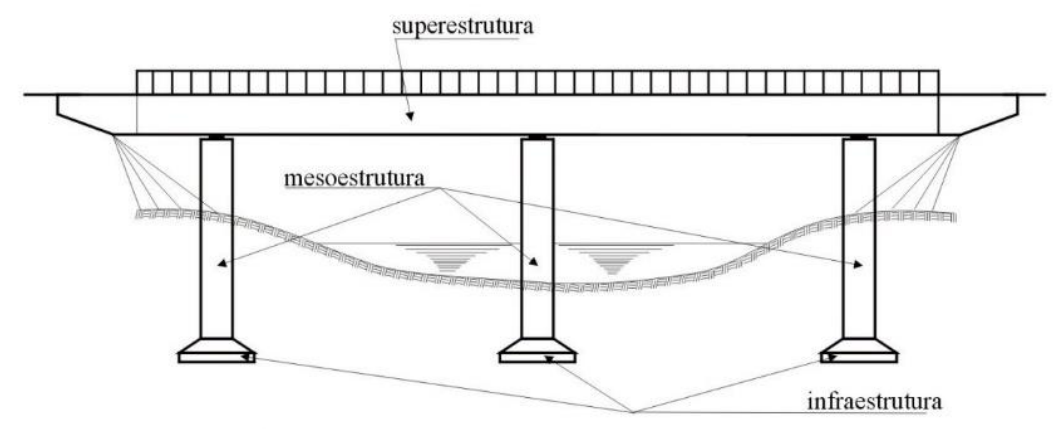

Figura 1 - Elementos estruturais componentes das pontes

Fonte: Vitório (2002)

\section{Origem das manifestações patológicas em pontes}

As pontes podem ser acometidas por manifestações patológicas comprometendo a funcionabilidade ao longo da sua vida útil. O desenvolvimento de manifestações patológicas pode estar correlacionado com as falhas na etapa de projeto, na seleção inadequada de materiais, na execução e/ou na utilização da estrutura de forma inadequada.

Em relação a utilização da ponte, vale salientar que além das manifestações patológicas oriundas da má utilização e da falta de manutenção, por exemplo, outro fator a ser ressaltado é que as estruturas se encontram em ambiente de alta agressividade ambiental e estão suscetíveis a solicitações excepcionais devido a acontecimentos atípicos, como inundações (MENDES et al., 2010; VITÓRIO, 2002).

Considerando que a ocorrência de manifestações patológicas é um fenômeno comum entre as pontes e viadutos em todo o mundo (LOURENÇO et al., 2009), nesse contexto, a Figura 2 apresenta uma distribuição percentual das origens dos problemas patológicos das estruturas em diversos países, nas etapas construtivas e no uso. Nota-se que no Brasil, a maioria das falhas são apresentadas na etapa de execução. 


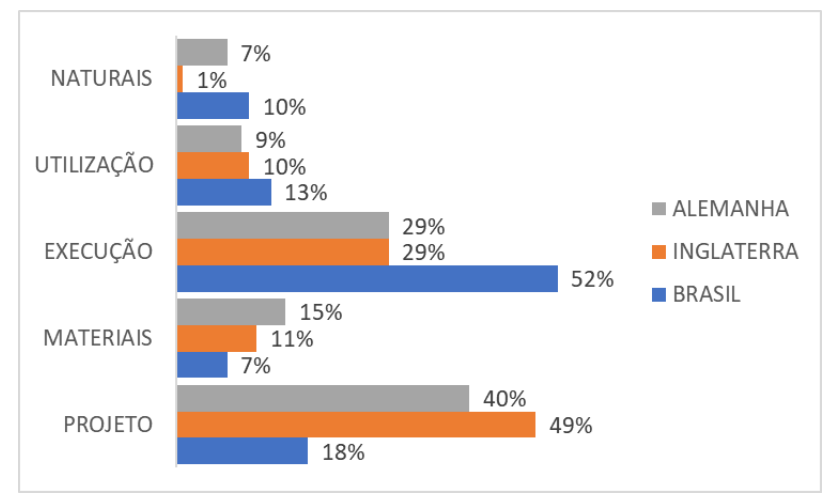

Figura 2 - Distribuição da origem das manifestações patológicas em estruturas

Fonte: Pelacani (2010), adaptada pelos autores

\section{Causas e principais manifestações patológicas em pontes}

De acordo com Santos e Vitório (2016), um diagnóstico eficaz das manifestações patológicas deve envolver todos os aspectos, sendo eles: origem, causas, mecanismos e sintomas. Nesse contexto, considerando que além da tendência natural da deterioração das estruturas com seu envelhecimento, as deteriorações podem ser ocasionadas devido a agentes mecânicos e químicos, de forma isolada ou simultânea (MASCARENHAS et al., 2019).

\subsection{Manifestações patológicas causadas por agentes mecânicos}

As mais relevantes manifestações patológicas causadas por agentes mecânicos são as fissurações e a abrasão do concreto, devido aos esforços estruturais os quais as pontes estão submetidas e devido os atritos e choques nas superfícies da estrutura (SILVA, 2011; MASCARENHAS et al., 2019).

As fissuras são aberturas que podem se apresentar de diferentes formas, podendo ser classificadas como ativas, quando a abertura aumenta ao longo do tempo e/ou a exposição de cargas móveis, ou passivas, quando estão estabilizadas (DNIT, 2010; VITÓRIO 2002).

A abrasão pode ser entendida como o desgaste do concreto superficial, podendo ocasionar a perda da resistência mecânica, que ocorre devido a atuação do atrito de materiais sólidos, arranhamento, ar e águas nas superfícies das estruturas, e sua intensidade depende de fatores como a qualidade do concreto, a dureza das partículas, etc. (SILVA, 2011; SOUZA; RIPPER, 1998).

\subsection{Manifestações patológicas causadas por agentes químicos}

Situadas em ambientes de alta agressividade ambiental as pontes estão expostas a agentes químicos que em contato com o concreto desencadeiam reações causando manifestações patológicas, como a corrosão das armaduras, a carbonatação e a lixiviação.

A corrosão das armaduras pode ser entendida como o processo de deterioração do material metálico por ações químicas ou eletroquímicas. A corrosão das armaduras é gradativa, pois devido a continuidade do processo supracitado provoca a redução na seção da armadura e até sua total destruição, assim comprometendo sua resistência e, consequentemente, pondo em risco a segurança da estrutura (BERTI et al., 2019; VITÓRIO 2002).

Com ocorrência frequente, a carbonatação se caracteriza pela diminuição da alcalinidade do cimento devido a reação do hidróxido de cálcio, com pH alto, com compostos do meio, resultando na formação de sais de cálcio, com pH mais neutro (MENDES et al., 2010; VITÓRIO, 2002).

A lixiviação ocorre devido a infiltração de águas no concreto, sendo responsável por dissolver e carrear compostos hidratados da pasta de cimento. A lixiviação acarreta a redução de resistência mecânica, assim como pode ser indesejada por fatores estéticos (ABNT, 2014; SANTOS; INTERLANDI, 2016). Este processo favorece a incidência de outras manifestações patológicas, por exemplo, durante o seu processo pode-se 
formar depósitos de sais na supefície da estrutura, em forma de manchas brancas, tal fenômeno é conhecido como eflorescência (SANTOS; VITÓRIO, 2016).

\section{Estudo de caso da Ponte de Laje Grande em Catende-PE}

A Ponte de Laje Grande encontra-se sobre trecho do Rio Una que passa na área rural do munícipio de Catende, localizado na Zona da Mata Sul de Pernambuco. O final do mês de maio de 2017 foi marcado pela incidência de chuvas acima da média em diversas cidades da região, Tabela 1, que ocasionaram inundações e diversos outros estragos, entre eles danos às pontes. Observado o histórico de precipitação dos últimos cinco anos, Tabela 2, no ano de 2017 ocorreu o maior volume precipitado para a cidade de Catende, justificando o evento de cheia ocorrido, que ao somar com ações antrópicas negativas que levam ao processo de assoreamento dos rios, como retirada da camada de proteção vegetal, a ocupação inadequada de suas margens e retificação dos mesmos, geram danos severos e abragentes.

Tabela 1 - Precipitação acumulada em maio de 2017, média mensal para maio e desvio da média em cidades da Mata Sul de Pernambuco

\begin{tabular}{cccc}
\hline CIDADE & ACUMULADO (MM) & MÉDIA (MM) & DESVIO (\%) \\
\hline BELÉM DE MARIA & 446 & 117 & $\mathbf{2 8 0}$ \\
\hline CATENDE & 581 & 154 & $\mathbf{2 7 8}$ \\
\hline CORTÊS & 504 & 248 & $\mathbf{1 0 3}$ \\
\hline RIBEIRÃO & 521 & 215 & $\mathbf{2 0 5}$ \\
\hline
\end{tabular}

Fonte: APAC (2017), adaptada pelos autores

Tabela 2 - Histórico de precipitação acumulada no mês de maio em Catende-PE, entre 2015 e 2020

\begin{tabular}{ccc}
\hline POSTO & ANO & HISTÓRICO DE CHUVA (MM) \\
\hline $\mathbf{5 2 7}$ - Catende & 2016 & $\mathbf{1 8 3 , 0}$ \\
\hline $\mathbf{5 2 7}$ - Catende & 2017 & 580,9 \\
\hline $\mathbf{5 2 7}$ - Catende & 2018 & 169,3 \\
\hline $\mathbf{5 2 7}$ - Catende & 2019 & 103,7 \\
\hline $\mathbf{5 2 7}$ - Catende & 2020 & 304,3 \\
\hline
\end{tabular}

Fonte: Elaborada pelos autores com dados da APAC (2020)

Construída a cerca de 25 anos no distrito de Laje Grande, utilizando concreto armado e pedra argamassada, a Ponte de Laje Grande, Figura 3, possui uma extensão de 115,00 metros e largura de 4,50 metros.

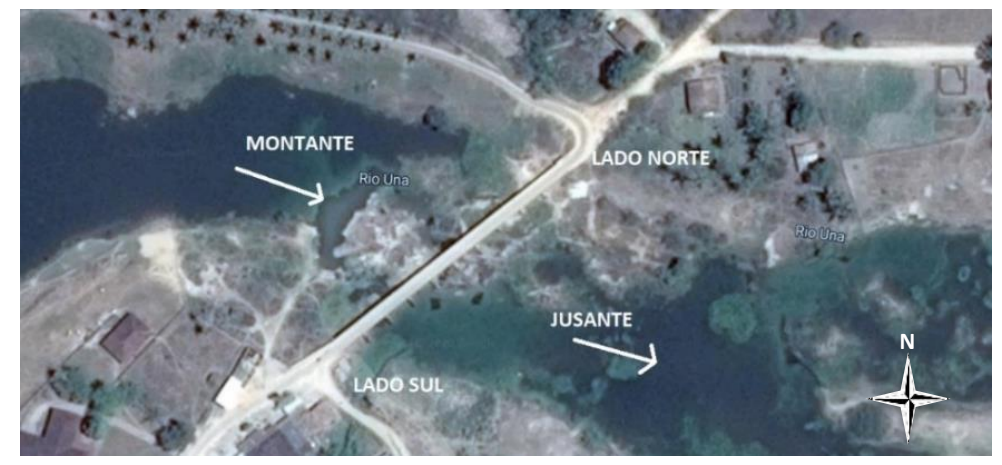

Figura 3 - Vista de satélite da Ponte de Laje Grande

Fonte: Google Maps (2020), adaptada pelos autores

Em relação aos encontros, o material utilizado no lado norte da ponte foi o concreto armado, e no lado sul, foi pedra argamassada. A superestrutura da ponte, representada na Figura 4, é constituída de um tabuleiro de concreto armado de altura de 0,80 metros e 4,00 metros de fundo. A ponte possui uma faixa de rolamento revestida de concreto e apenas um passeio de pedestre do lado montante da ponte com guarda corpo, 
havendo no lado jusante apenas um guarda rodas simples. Para escoamento das águas pluvias, a ponte conta com um total de 24 tubos de drenagem com o diâmetro de $\varnothing 75 \mathrm{~mm}$, nas margens direita e esquerda.

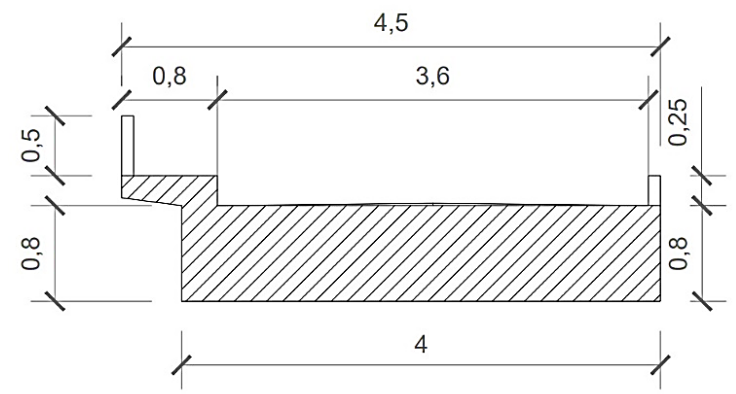

Figura 3 - Geometria da superestrutura da Ponte de Laje Grande

Fonte: Autores

A mesoestrutura é composta por 9 pilares, formando 10 vãos que variam de 8 a 9 metros, sendo os 3 primeiros (sentido norte-sul) de concreto armado e o outros 6 construídos em pedra argamassada. Os pilares possuem geometria retangular com largura de 1,00 metro e comprimento de 7,50 metros, aproximadamente, tendo as extremidades em forma triangular, a fim de reduzir a ação dinâmica do Rio Una sobre a ponte. Vale ressaltar que não há aparelhos de apoio entre superestrutura e mesoestrutura. Em relação a infraestrutura, considerando que parte está submersa na água do rio, é possível identificar que a fundação é formada por sapatas isoladas de concreto armado, construída diretamente sobre a rocha superficial.

\subsection{Metodologia aplicada}

Para elaboração do estudo de caso foi realizada uma análise dos dados apresentados no relatório técnico elaborado e disponibilizado pelo Conselho Regional de Engenharia e Agronomia de Pernambuco (CREA-PE), pertencentes ao Projeto de Apoio Técnico do CREA-PE aos municípios em Estado de Emergência da Mata Sul do estado, após as fortes chuvas do mês de maio de 2017, sendo o relatório resultado da inspeção visual da Ponte de Laje Grande realizada por um corpo de engenheiros civis voluntários do CREA-PE. Vale ressaltar que não houve acesso aos projetos da ponte em estudo. Além disso, foi feita a comparação dos resultados encontrados com os dados da literatura, assim como a proposição de soluções de recuperação dos danos identificados na Ponte de Laje Grande.

\subsection{Análise das manifestações patológicas}

Na superestrutura, na parte superior do tabuleiro foi possível observar a ineficiência do sistema de drenagem, uma vez que a faixa de rolamento apresentava o acúmulo de lama e pontos de alagamento, assim como a degradação do guarda corpo em trechos da ponte, colocando em risco os usuários. Além disso, foi observado o desgaste por abrasão do revestimento da faixa de rolamento, deixando o agregado graúdo exposto e, consequentemente, levando a perda da resistência mecânica do revestimento.

$\mathrm{Na}$ lateral do tabuleiro devido a ausência de pingadeiras, os tubos do sistema de drenagem desaguam diretamente na superfície do tabuleiro, gerando infiltração, e consequentemente, promovendo o fenômeno da lixiviação, sendo observado a presença de manchas brancas características de eflorescências. Assim como, na mesoestrutura, foram observadas a presença do processo da lixiviação e eflorescência nos encontros.

$\mathrm{Na}$ lateral e parte inferior do tabuleiro foram identificadas fissuras e pontos de corrosão da armadura em estado avançado, uma vez que a barra de aço apresentava seção reduzida e as tensões geradas com a expansão dos produtos de corrosão já tinham ocasionado desplacamento de concreto na região afetada.

Na mesoestrutura, os pilares também apresentaram pontos de corrosão da armadura e fissuras, com origens possíveis no projeto e/ou na execução, devido a cobrimento especificado inadequadamente e/ou falhas 
durante o processo de concretagem, respectivamente. A falta de acesso aos projetos não permitiram obter informações para distinguir a qual dessas origens de fato está relacionada o cobrimento inadequado

Além disso, foi identificada a presença de desgate superficial do concreto nas sapatas devido à abrasão com exposição do agregado graúdo, consequência da ação das águas do rio sobre a estrutura, assim como de um possível cobrimento de espessura inferior ao recomendado por norma. Também foi verificado o crescimento de vegetação, assim como vegetação presa entre a superestrutura e a mesoestrutura, advinda da correnteza do rio, favorecendo a exposição do concreto a outros agentes agressivos, como também o acúmulo de novas vegetações carreadas pelo rio e, consequentemente, aumentando a área de influência da água na estrutura. No Quadro 1 é apresentado o resumo das manifestações patológicas encontradas na estrutura, suas possíveis causas e seus registros fotográficos, assim como das sugestões para recuperação da estrutura.

Quadro 1 - Resumo das manifestações patológicas identificadas na superestrutura.

\begin{tabular}{|c|c|c|c|}
\hline $\begin{array}{l}\text { MANIFESTAÇÕES } \\
\text { PATOLÓGICAS }\end{array}$ & POSSÍVEIS CAUSAS & REGISTROS FOTOGRÁFICOS ${ }^{4}$ & PROPOSTA DE RECUPERAÇÃO \\
\hline ABRASÃO & $\begin{array}{c}\text { - EXCESSO DE CARGA } \\
\text { - AÇÃO DAS ÁGUAS } \\
\text { DO RIO } \\
\text { - CONCRETO DE } \\
\text { BAIXA QUALIDADE }\end{array}$ & & $\begin{array}{c}\text { - RECAPEAMENTO DO } \\
\text { REVESTIMENTO DA FAIXA DE } \\
\text { ROLAMENTO } \\
\text { - RECUPERAÇÃO COM } \\
\text { CONCRETO DE BOA } \\
\text { RESITÊNCIA À ABRASÃO }\end{array}$ \\
\hline $\begin{array}{l}\text { DEGRADAÇÃO DO } \\
\text { GUARDA CORPO }\end{array}$ & $\begin{array}{c}\text { - CHOQUE DE } \\
\text { OBJETO/VEGETAÇÃO } \\
\text { - AÇÃ̃O DAS ÁGUAS }\end{array}$ & & $\begin{array}{c}\text { - RECONSTRUÇÃO DO GUARDA } \\
\text { CORPO }\end{array}$ \\
\hline LIXIVIAÇÃO & $\begin{array}{l}\text { - INFILTRAÇÃO } \\
\text { - POROSIDADE }\end{array}$ & & $\begin{array}{l}\text { - RECUPERAÇÃO DO SISTEMA } \\
\text { DE DRENAGEM } \\
\text { - LIMPEZA E RECUPERAÇÃO } \\
\text { DO CONCRETO AFETADO }\end{array}$ \\
\hline EFLORESCÊNCIA & $\begin{array}{l}\text { - INFILTRAÇÃO } \\
\text { - POROSIDADE } \\
\text { - LIXIVIAÇÃO }\end{array}$ & & $\begin{array}{c}\text { - RECUPERAÇÃO E } \\
\text { MANUTENÇÃO DO SISTEMA } \\
\text { DE DRENAGEM } \\
\text { - LIMPEZA E RECUPERAÇÃO } \\
\text { DO CONCRETO AFETADO }\end{array}$ \\
\hline $\begin{array}{l}\text { CORROSÃO DA } \\
\text { ARMADURA }\end{array}$ & $\begin{array}{l}\text { - INFILTRAÇÃO } \\
\text { - FISSURAS } \\
\text { - COBRIMENTO } \\
\text { INSUFICIENTE } \\
\text { - POROSIDADE } \\
\text { - CARBONATAÇÃO }\end{array}$ & & $\begin{array}{c}\text { - TRATAR ORIGEM DO } \\
\text { PROBLEMA } \\
\text { - LIMPAR A REGIÃO AFETADA } \\
\text { - REFORÇO ESTRUTURAL } \\
\text { - PROTEÇÃO QUÍMICA } \\
\text { - PREENCHER O VAZIO COM } \\
\text { GRAUTE OU SIMILAR }\end{array}$ \\
\hline
\end{tabular}

${ }^{4}$ Imagens disponibilizadas pelo CREA-PE através do e-mail: asspe.creape@gmail.com 


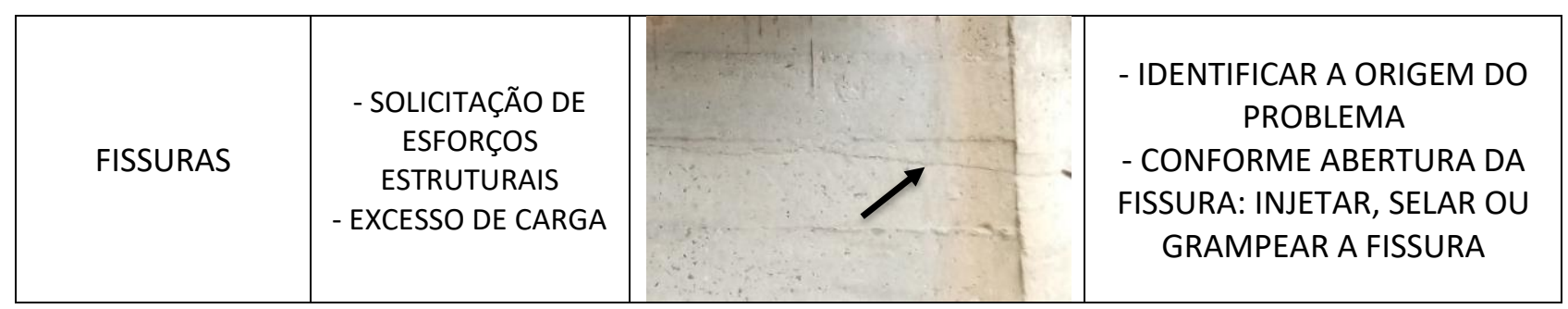

Fonte: Elaborado pelos autores

Considerando que não houve acesso aos registros das condições de conservação antes do advento das chuvas de maio de 2017 da ponte estudada, diante das manifestações patológicas e danos identificados, pode-se inferir que a maioria são característicos de pré-existentes, sendo a vegetação presa na estrutura, o acúmulo de lama, os pontos de alagamento e, em parte, os danos ao guarda corpo resultado da ação das águas, devido a elevação da cota do rio durante as chuvas. Vale ressaltar que a água está envolvida na maioria dos processos de deterioração, acelerando e/ou desencadeando manifestações patológicas, logo faz-se necessário a criação de um plano de inspeção e manutenção preventiva, para preservação da integridade e da funcionabilidade da estrutura.

\section{Considerações Finais}

A ocorrência de manifestações patológicas em obras de artes é comum, pois além da exposição das estruturas a ambientes de alta agressividade ambiental, deixando-as suscetíveis a solicitações excepcionais, o concreto armado apresenta uma tendência natural de deterioração. Além disso, outros fatores como falhas de concepção, execução e uso das estruturas também dão origem ao surgimento de manifestações patológicas.

Identificar e avaliar as manifestações patológicas, assim conhecer os seus agentes causadores é de suma importância para um diagnóstico eficaz, permitindo agregar uma maior qualidade aos métodos de reparo e, consequentemente, estender a durabilidade das estruturas, prologando sua vida útil e garantindo a segurança dos seus usuários.

A partir do estudo de caso da Ponte de Laje Grande, foi possível exemplificar os conceitos abordados em um caso real. Foi observado que a Ponte de Laje Grande foi acometida pela incidência de chuvas que causaram inundações em diversas cidades da Mata Sul pernambucana em maio de 2017, demonstrando estar suscetível a solicitações excepcionais, que ajudam a desencadear e/ou acelerar os processos que causam manifestações patológicas.

$\mathrm{Na}$ Ponte de Laje Grande foram identificadas diversas manifestações patológicas em seus elementos estruturais, essas que possivelmente são consequências da combinação da agressividade do meio que está situada, destacando a ação direta da água durante eventos intensos de chuva e constante umidade, e da tendência natural de deterioração do concreto, juntamente com possíveis falhas de projeto, concepção, uso inadequado e falta de manutenção preventiva. A fim de contribuir para revitalização da estrutura, sugestões de recuperação foram apontadas.

Diante das manifestações patológicas e dos danos estruturais apresentados no estudo, é indispensável a prática de inspeção periódica para avaliação do estado da estrutura e a prática de manutenção preventiva, ambas em consonância com as normas vigentes, a fim de elevar o tempo de vida útil da estrutura, assegurando evitar o comprometimento da sua funcionabilidade e a garantia da segurança dos usuários. Espera-se com o trabalho desenvolvido contribuir com a ampliação do conhecimento acerca do tema, e consequentemente, com a preservação dessas obras de artes especiais.

\section{Agradecimentos}

Os autores agradecem ao Conselho Regional de Engenharia e Agronomia de Pernambuco (CREA-PE) por disponibilizar o material que serviu de base para desenvolvimento deste trabalho. 


\section{Referências Bibliográficas}

AGÊNCIA PERNAMBUCANA DE ÁGUAS E CLIMA - APAC. Boletim do clima: Síntese climática, Recife, v. 5, n. 5, p. 1-47, $2017 . \quad$ Disponível em: http://www.sirh.srh.pe.gov.br/apac/arquivos_portal/boletins/Boletim\%20climatico\%20\%20Maio_2017.pdf. Acesso em: 07 de out. 2020.

Meteorologia: Histórico de Chuvas. Disponível em: http://old.apac.pe.gov.br/meteorologia/monitoramento-pluvio.php. Acesso em: 06 de out. 2020.

ASSOCIAÇÃO BRASILEIRA DE NORMAS TÉCNICAS - ABNT. NBR 6118: Procedimento de estruturas de concreto - Procedimento. Rio de Janeiro: ABNT, 2014.

BERTI, J. V. M. et al. Estudo da origem, sintomas e incidências de manifestações patológicas do concreto. Revista Científica ANAP Brasil, v. 12, n. 26, p. 33-47, 2019. Disponível em: http://www.amigosdanatureza.org.br/publicacoes/index.php/anap_brasil/issue/view/203. Acesso em: 05 de out. 2020.

CONSELHO REGIONAL DE ENGENHARIA E AGRONOMIA DE PERNAMBUCO - CREA-PE. Projeto de Apoio Técnico do CREA-PE aos Municípios da Mata Sul em Estado de Emergência: Relatório Final Catende-PE. Recife, 2017. Disponível em: https://www.creape.org.br/portal/wpcontent/uploads/2019/02/Relat\%C3\%B3rio-Catende.pdf. Acesso em: 8 de set. 2020.

DEPARTAMENTO NACIONAL DE INFRAESTRUTURA DE TRANSPORTES - DNIT. Manual de recuperação de pontes e viadutos rodoviários. Rio de Janeiro, 2010.

LOURENÇO, L. C. et al. Parâmetros de Avaliação de Patologias em Obras-de-Arte Especiais. Revista Engenharia Civil, Braga n. 34, p 5-14, 2009. Disponível em: http://www.civil.uminho.pt/revista/artigos/n34/Pag_5-14.pdf. Acesso em: 16 set. 2020.

MARCHETTI, O. Pontes de Concreto Armado. 2. ed. - São Paulo: Blucher, 2018.

MASCARENHAS, F. J. R. et al. Patologias e inspeção de pontes em concreto armado: Estudo de caso da ponte Governador Magalhães Pinto. Engevista, v. 21, n. 2, p. 288-302, 2019. Disponível em: https://periodicos.uff.br/engevista/article/view/27125. Acesso em: 19 de set. 2020.

MENDES, L. C. et al. Pontes em concreto armado em meios de elevada agressividade ambiental. In: CONGRESO INTERNACIONAL SOBRE PATOLOGÍA Y RECUPERACIÓN DE, 6, 2010, Córdoba, Argentina, 2010. Disponível em: http://www.edutecne.utn.edu.ar/cinpar_2010/Topico\%201/CINPAR\%20073.pdf. Acesso em: 15 set. 2020.

PELACANI, V. L. Cadernos do CREA-PR: № 7-Responsabilidade na Construção Civil. Curitiba: CREA-PR, 2010.

SANTOS, D.; VITÓRIO, J. Um Estudo das Manifestações Patológicas e das Condições Estruturais da Ponte sobre o Rio Igarassu na BR 101/PE. Revista de Engenharia e Pesquisa Aplicada, v. 3, n. 1, 2016. Disponível em: http://revistas.poli.br/index.php/repa/article/view/537. Acesso: 17 de set. 2020.

SANTOS; B. O. C.; INTERLANDI, C. Estruturas de Concreto Armado - Patologias e suas Consequências - Estudo de Caso. Engenharia Estudo e Pesquisa. ABPE, v. 16, n. 2, p. 40-47, 2016. Disponível em: http://www.abperevista.com.br/imagens/volume16_02/cap05.pdf. Acesso em: 19 de set. 2020.

SILVA, L. K. Levantamento de manifestações patológicas em estruturas de concreto armado no estado do Ceará. 2011. Trabalho de Conclusão de Curso (Graduação em Engenharia Civil) - Universidade Federal do Ceará, $\quad$ Fortaleza, $2011 . \quad$ Disponível em: http://www.deecc.ufc.br/Download/Projeto_de_Graduacao/2011/Luiza_Kilvia_Levantamento\%20de\%2 OManifestacoes\%20Patologicas\%20em\%20Estruturas\%20de\%20Concreto\%20Armado\%20no\%20Estado \%20do\%20Ceara.pdf. Acesso em: 02 de out. 2020.

SOUZA, V. C.; RIPPER, T. Patologia, recuperação e reforço de estruturas de concreto. 1 ed. São Paulo: Pini, 1998.

VITÓRIO, J. A. P. Pontes rodoviárias: fundamentos, conservação e gestão. 1. ed. Recife: CREA-PE, 2002. 